\title{
Corrigendum: A catalytically silent FAAH-1 variant drives anandamide transport in neurons
}

Jin Fu, Giovanni Bottegoni, Oscar Sasso, Rosalia Bertorelli, Walter Rocchia, Matteo Masetti, Ana Guijarro, Alessio Lodola, Andrea Armirotti, Gianpiero Garau, Tiziano Bandiera, Angelo Reggiani, Marco Mor, Andrea Cavalli \& Daniele Piomelli Nat. Neurosci. 15, 64-69 (2012); published online 20 November 2011; corrected after print 15 December 2011

In the version of this article initially published, ref. 36 (given as Kaczowka, S.J. et al. Int. J. Biol. Macromol. 42, 62-67, 2008) was incorrect. The correct reference is Kaczocha, M., Glaser, S.T. \& Deutsch, D.G. Identification of intracellular carriers for the endocannabinoid anandamide. Proc. Natl. Acad. Sci. USA 106, 6375-6380 (2009). The error has been corrected in the HTML and PDF versions of the article.

Corrigendum: Control of timing, rate and bursts of hippocampal place cells by dendritic and somatic inhibition

Sébastien Royer, Boris V Zemelman, Attila Losonczy, Jinhyun Kim, Frances Chance, Jeffrey C Magee \& György Buzsáki

Nat. Neurosci. 15, 769-775 (2012); published online 25 March 2012; corrected after print 5 June 2012

In the version of this article initially published, the Figure 3a legend described the ripple-activated neurons as representing oriens-lacunosum moleculare interneurons and the ripple-suppressed as representing bistratified interneurons. The reverse is true. The error has been corrected in the HTML and PDF versions of the article.

Corrigendum: The neuroscience of empathy: progress, pitfalls and promise Jamil Zaki \& Kevin Ochsner

Nat. Neurosci. 15, 675-680; published online 15 April 2012; corrected after print 30 April 2012

In the version of this article initially published, the middle initial of author Kevin N. Ochsner was omitted. The error has been corrected in the HTML and PDF versions of the article.

\section{Erratum: Orthogonal micro-organization of orientation and spatial frequency in primate primary visual cortex}

Ian Nauhaus, Kristina J Nielsen, Anita A Disney \& Edward M Callaway

Nat. Neurosci. 15, 1683-1690 (2012); published online 11 November 2012; corrected after print 3 December 2012

In the version of this article initially published, the scale bar length for Figure 1e was misstated as $500 \mu \mathrm{m}$. The correct length is $50 \mu \mathrm{m}$. The error has been corrected in the HTML and PDF versions of the article.

\section{Corrigendum: Orthogonal micro-organization of orientation and spatial frequency in primate primary visual cortex}

Ian Nauhaus, Kristina J Nielsen, Anita A Disney \& Edward M Callaway

Nat. Neurosci. 15, 1683-1690 (2012); published online 11 November 2012; corrected after print 9 January 2013

In the version of this article initially published, the computation performed to yield the values on the $x$ axis of Figure $6 \mathrm{c}$ was incorrectly defined in the text and on the axis label as the absolute difference between $A_{\theta}$ and $A_{\phi}\left(\bmod 90^{\circ}\right)$. The correct computation is $90^{\circ}-|| A_{\theta}-A_{\phi}\left|-90^{\circ}\right|$, which yields values near $0^{\circ}$ for parallel gradients and values near $90^{\circ}$ for perpendicular gradients. The error has been corrected in the HTML and PDF versions of the article. 